\title{
An Experimental Study on the Ordered Alloy $\mathrm{Ni}_{2} \mathrm{Cr}$
}

\author{
By Makoto Hirabayashi*, Masahiro Koiwa*, Kyoko Tanaka*, \\ Tsugio Tadaki**, Toshio Saburi***, Soji Nenno*** \\ and Hideki Nishiyama*****
}

\begin{abstract}
The ordered alloy $\mathrm{Ni}_{2} \mathrm{Cr}$ has been investigated by means of electron diffraction, electron microscopy, calorimetry, resistometry and tensile tests. The formation of the $\mathrm{Pt}_{2} \mathrm{Mo}$ type superstructure is revealed by an electron diffraction study on the single crystalline specimens. The size of ordered domains is of the order of magnitude of several hundred $\AA$ even in the well annealed state. The so-called ' $K$-state' which is characterized by the initial increase in electrical resistivity upon isothermal annealing is attributed to the existence of very fine ordered domains. Superdislocations consisting of triple dislocations are sometimes observed in various stages of ordering, and the mechanical properties are briefly discussed in the light of electron microscopic observation. The energy and entropy of transformation are evaluated as about $1.0 \mathrm{kcal} / \mathrm{g} \cdot$ atom and $1.2 \mathrm{cal} / \mathrm{g} \cdot$ atom-deg on the alloy of $32.1 \mathrm{at} \% \mathrm{Cr}$ annealed at $500^{\circ} \mathrm{C}$ for about $3000 \mathrm{hr}$.
\end{abstract}

(Received April 11, 1969)

\section{Introduction}

Although numerous works have so far been carried out on the order-disorder transformation of alloys of the $A_{3} B$ and $A B$ types, a rather limited number of studies have been done on the alloys of the $A_{2} B$ type. For the nickel-chromium system, Baer ${ }^{(1)}$ and Bagariatskii and Tiapkin ${ }^{(2)}$ observed the existence of the superlattice $\mathrm{Ni}_{2} \mathrm{Cr}$ by an X-ray diffraction technique, and Goman'kov et al. ${ }^{(3)}$ confirmed it by a neutron diffraction study. The atomic arrangement of this ordered alloy is isomorphous with the $\mathrm{Pt}_{2} \mathrm{Mo}$ type, the space group $\mathrm{D}_{2 \mathrm{~h}}^{25}-\mathrm{Immm}$ (No. 71). The orthorhombic unit cell containing six atoms has the lattice parameters $a \simeq a_{0} / \sqrt{2}, b \simeq 3 \quad a_{0}$ / $\sqrt{2}$ and $c \simeq a_{0}$, where $a_{0}$ is that of the original $f c c$ cell (see Fig. 3).

Several workers ${ }^{(1)(4) \sim(8)}$ observed anomalous changes in physical and mechanical properties of this alloy long before the crystal structure of the ordered state had been

* The Research Institute for Iron, Steel and Other Metals, Tohoku University, Sendai, Japan.

** The Research Institute for Iron, Steel and Other Metals, Tohoku University, Sendai. Present address : The Institute of Scientific and Industrial Research, Osaka University, Suita, Japan.

*** Department of Metallurgy, Faculty of Engineering, Osaka University, Suita, Japan.

***** Department of Metallurgy, Faculty of Engineering, Osaka University, Suita. Present address : Mitsubishi Steel Manufacturing Co., Nagasaki, Japan.

(1) H. G. Baer : Z. Metallk., 49 (1958), 614 ; Naturwiss., 43 (1956), 298.

(2) Iu. A. Bagariatskii and Iu. D. Tiapkin : Sov. Phys. Doklady, $3(1958), 1025$.

(3) V. I. Goman'kov, D. F. Litvin, A. A. Loshmanov and B. G. Lyashchenko : Phys. Met. and Metallog., 14 (1.962), No. 2, 133.

(4) Z. Yano : Bull. Inst. Phys. Chem. Research, 19(1940), 110.

(5) A. Taylor and K. G. Hinton : J. Inst. Metals, 81 (1952 53), 169.

(6) R. Nordheim and N. J. Grant : J. Inst. Metals, 82(1953 54), 440.

(7) H. Masumoto, M. Sugihara and M. Takahashi : J. Japan Inst. Metals, 18 (1954), 85.

(8) W. Köster and P. Rocholl : Z. Metallk., 48 (1957), 485.

Trans. J I M established. For instance, the temperature coefficient of electrical resistivity is negative around $600^{\circ} \mathrm{C}$ and the resistivity of the quenched alloy increases initially with time during isothermal annealing. The state of an alloy showing such a peculiar behavior is often called the " $K$ state" though little is known about its microstructure.

Recently Popov et al. ${ }^{(9)(10)}$ investigated the nature of dislocations and the effect of atomic order on the work-hardening in $\mathrm{Ni}_{2} \mathrm{Cr}$. It was suggested from the atomic arrangements on the slip planes that in eight of the twelve slip systems no anti-phase boundaries are created by a slip dislocation, while single dislocations in the remaining four systems form anti-phase boundaries, thus forming superdislocations which consist of three dislocation lines linked in a pair with strips of anti-phase boundaries. However, the triple dislocations have not yet actually been revealed by electron-microscopic observation.

A statistical theory on the order-disorder transformation of the $\mathrm{Pt}_{2}$ Mo type was presented by Shtremel ${ }^{(11)}$, but no thermodynamical data on the stoichiometric alloy $\mathrm{Ni}_{2} \mathrm{Cr}$ were available for quantitative comparison with the calculation.

A joint effort has been made by two groups of the present authors (Tohoku Univ. and Osaka Univ.) to investigate the nature of the ordered alloy $\mathrm{Ni}_{2} \mathrm{Cr}$ by a comprehensive method of electron microscopy, electron diffraction, calorimetry, resistometry and mechanical tests. Experimental works were independently carried out by the two groups, but the observed results were consistent with each other as described in the later sections. The present paper will mostly deal with changes in thermodynamical quantities due to the orderdisorder transition, and microscopic configurations of ordered domains and of superdislocations. The observed

(9) L. Ye. Popov and E. V. Kozlov : Phys. Met. and Metallog., 18 (1964), No. 1, 102.

(10) L. Ye. Popov, E. V. Kozlov, N. M. Matveyeva and I. A. Tsukanova : Phys. Met. and Metallog., 23 (1967), No. 4, 189.

(11) M.A. Shtremel : Phys. Met. and Metallog., 20 (1965), No. 6, 28.

1969 Vol. 10 
results of electron microscopy will be discussed in relation to the changes in the physical and mechanical properties.

\section{Experimental Procedures}

Four specimens containing $32.1,32.9,33.3$ and 35.2 at \% $\mathrm{Cr}$ were prepared by vacuum-melting of the required amounts of the constituent metals. Chromium contents of the specimens were determined by chemical analysis. In this comprehensive study, the work of Saburi et al. was concentrated on an alloy of 35.2 at $\%$ $\mathrm{Cr}$, while the effort of Hirabayashi et al. was made for the other three alloys.

Calorimetric measurements were made in vacuum by an adiabatic calorimeter using cylindrical specimens of about $50 \mathrm{~g}$ in weight. Measurements of the electrical resistivity were made at liquid-nitrogen temperature by a usual potentiometric method using specimens in the form of either a thin plate or wire. The wire specimens were also used for tensile tests at a strain rate of $5 \times 10^{-2}$ $\min ^{-1}$. Microhardness was measured under a load of $500 \mathrm{~g}$ using plate samples. Thin foils for observations by electron diffraction and electron microscopy were prepared by electropolishing sheet specimens 0.1 or $0.2 \mathrm{~mm}$ thick. Lattice constants were determined by means of X-ray powder diffraction using $\mathrm{Cu} K_{\alpha}$ radiation.

\section{Experimental Results}

\section{Calorimetry}

Anomalous thermal effects of the alloys near in composition to $\mathrm{Ni}_{3} \mathrm{Cr}$ have previously been observed by some workers $^{(5)(7)(12)}$, but no quantitative data have been available yet for the composition $\mathrm{Ni}_{2} \mathrm{Cr}$. In the present study, therefore, calorimetric measurements were performed up to about $700^{\circ} \mathrm{C}$ under vacuum on an alloy, 32.1 at \% Cr, after various heat treatments. The specific heat vs. temperature curves are given in Fig. 1. In this figure, a dotted curve $a$ was obtained after waterquenching of the specimen from $1000^{\circ} \mathrm{C}$. A small amount of heat evolution is observed around $530^{\circ} \mathrm{C}$. Since this was interpreted as the occurrence of atomic ordering during the heating measurement, the specimen was subsequently annealed to attain the ordered state at $500^{\circ} \mathrm{C}$ for $96 \mathrm{hr}$ after quenching again from $1000^{\circ} \mathrm{C}$. Then the second-run measurement was done as shown by the curve $b$. The third- and fourth-run meisurements were successively made on the specimen annealed for 480 and $2900 \mathrm{hr}$ at $500^{\circ} \mathrm{C}$, respectively. The results are drawn by the curves $c$ and $d$. An appreciable amount of heat absorption is observed on both the curves, indicating a fairly high degree of order obtained by the pre-treatment. The critical temperature of the orderdisorder transformation is estimated to be about $590^{\circ} \mathrm{C}$ from the location of the peak in the curves $c$ and $d$.

The heat absorption $(E)$ evaluated from these measurements is plotted against annealing time in Fig. 2 . The energy tends to reach a saturated value of about $1000 \mathrm{cal} / \mathrm{g} \cdot$ atom after annealing as long as $2900 \mathrm{hr}$,

(12) I. I. Kornilov and N. M. Matveyeva : Dokl. Akad. Nauk. SSSR, 139 (1961), 880. which is thought to be the heat of transformation $\left(E_{0}\right)$ of $\mathrm{Ni}_{2} \mathrm{Cr}$. The ordering at $500^{\circ} \mathrm{C}$ seems to be a first-order reaction from a linear relation between $\ln \left\{\left(E_{0}-E\right) / E_{0}\right\}$ and the annealing time, as depicted in this figure.

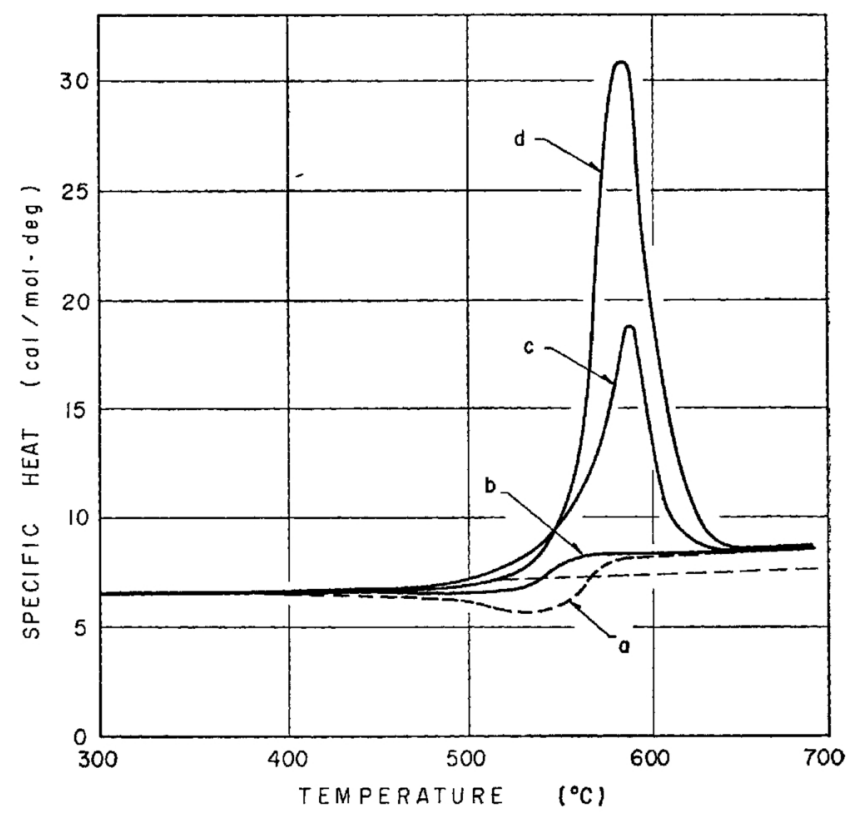

Fig. 1 Specific heat curves of $32.1 \% \mathrm{Cr}$ alloy. The alloy was initially quenched from $1000^{\circ} \mathrm{C}(\mathrm{a})$, then annealed at $500^{\circ} \mathrm{C}$ for $96 \mathrm{hr}(\mathrm{b}), 480 \mathrm{hr}(\mathrm{c})$ and $2900 \mathrm{hr}(\mathrm{d})$

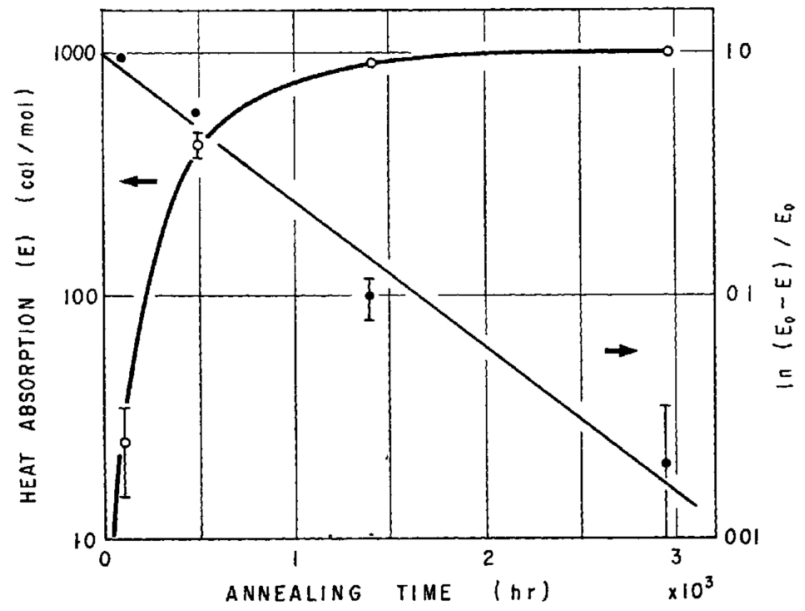

Fig. 2 Heat absorption against time of isothermal annealing at $500^{\circ} \mathrm{C}$

The entropy of transformation is evaluated as $1.2 \mathrm{cal} / \mathrm{g}$. atom-deg from the calorimetric measurement of the alloy annealed for $2900 \mathrm{hr}$. The change in configurational entropy $\Delta \Phi$ from the perfect order to the random distribution of the $\mathrm{A}_{2} \mathrm{~B}$ superlattice is theoretically given as

$$
\begin{aligned}
\Delta \Phi & =R\left(\ln 3-\frac{2}{3} \ln 2\right) \\
& =1.26 \mathrm{cal} / \mathrm{g} \cdot \text { atom }-\mathrm{deg},
\end{aligned}
$$

where $R$ is the gas constant. Consequently, there is an excellent agreement between the experimental value and calculation.

\section{Ordered structure of $\mathbf{N i}_{2} \mathbf{C r}$}

Electron diffraction studies and electron microscopic 
observations of fully annealed specimens were carried out in order to investigate the crystal structure and the ordered domains. The diffraction patterns of Photos. 1 (a), (b) and (c) (33.3 at \% Cu) show many superlattice reflections in the three reciprocal planes (001), (110) and (112) of the original $f c c$ lattice, respectively. These patterns can be interpreted in terms of the superstructure of the $\mathrm{Pt}_{2} \mathrm{Mo}$ type illustrated in Fig. 3. Figs. 3(a) and (b) show the atomic arrangement and the reciprocal only a single variant. In the $(\overline{11} 2)_{c}$ reciprocal plane (Photo. $1(\mathrm{c})$ ), there are thres variants.

Microscopic configurations of the ordered domains were examined by means of the dark-field image technique. A dark-field micrograph of the $(110)_{c}$ orientation shown in Photo. 2 (b) (33.3 at\% Cr) was formed by a superlattice spot (1/3 $\overline{1} / 3$ 1). A number of small bright regions are the ordered domains with the same orientation. Since the ordered domains have six equivalent

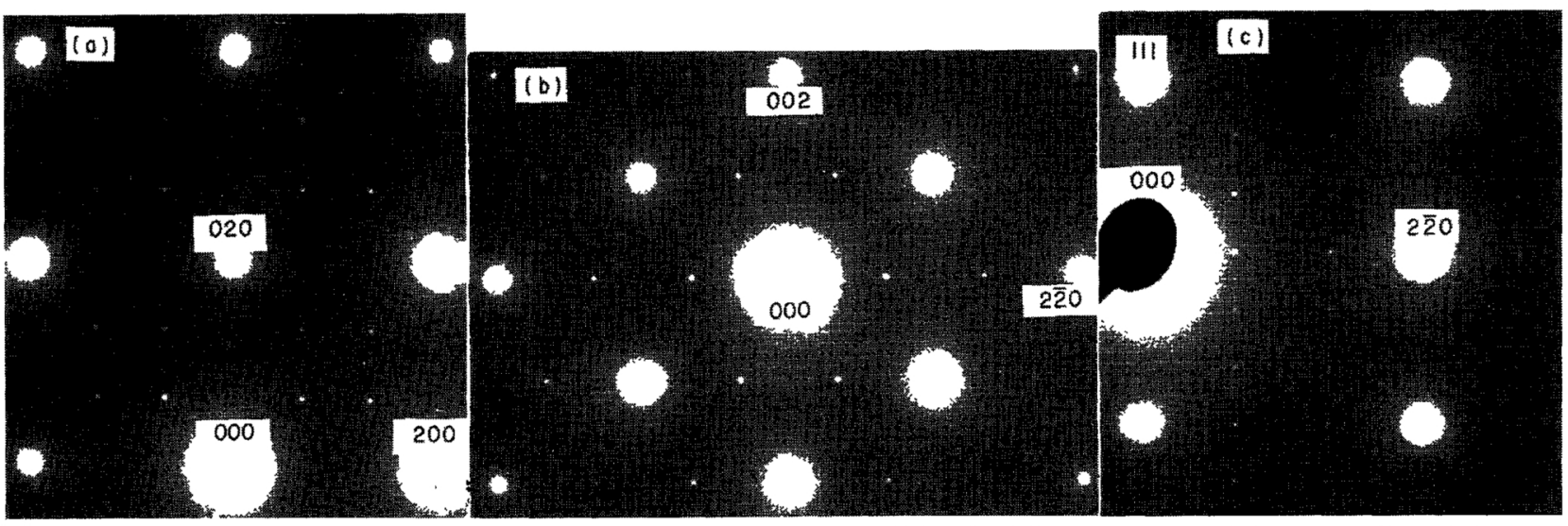

Photo. 1 Electron diffraction patterns of $33.3 \% \mathrm{Cr}$ alloy annealed at $500^{\circ} \mathrm{C}$ for $1600 \mathrm{hr}$. (a), (b) and (c) correspond to $(001)_{c}$, $(110)_{c}$ and $(\overline{11} 2)_{c}$ orientations, respectively. Schematic illustration is given in Fig. 4

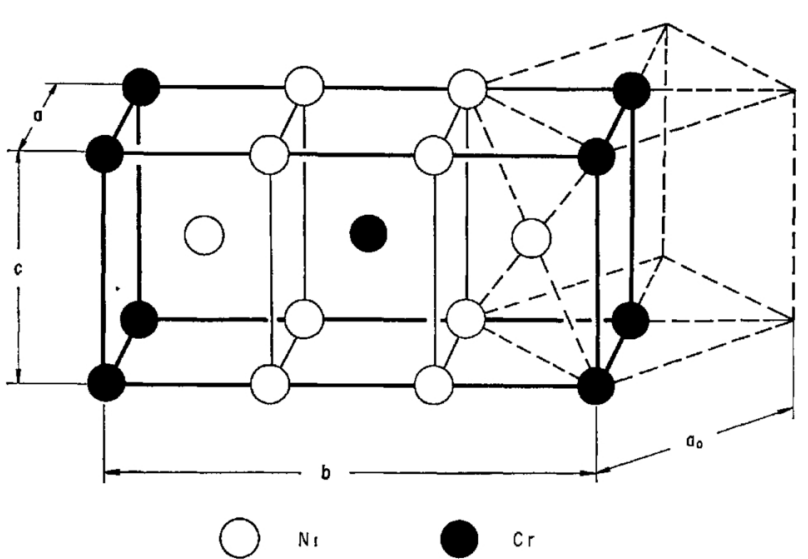

Fig. 3 (a) Ordered structure of $\mathrm{Ni}_{2} \mathrm{Cr}$. Broken lines indicate the original $f c c$ cell

lattice of the ordered alloy $\mathrm{Ni}_{2} \mathrm{Cr}$, respectively. The crystallographic relationships of the orientation between the ordered orthorhombic lattice and the disordered cubic lattice are given as follows :

$$
\text { and } \begin{aligned}
& {[100]_{r} / /[110]_{c}} \\
& {[010]_{r} / /[\bar{I} 10]_{c}}
\end{aligned}
$$

$$
[001]_{r} / /[001]_{c},
$$

where suffixes $r$ and $c$ refer to the orthorhombic and cubic lattices, respectively. This relationship consists with the results obtained from the X-ray study of Bagariatskii and Tiapkin ${ }^{(2)}$. It is interesting to note that there are six possible orientations equivalent with the above relation. As illustrated in Fig. 4, therefore, the superlattice spots observed in the $(001)_{c}$ reciprocal plane (Photo. $1(\mathrm{a})$ ) consist of those from two different variants, whereas those in the $(110)_{c}$ reciprocal plane (Photo. $1(b)$ ) come from

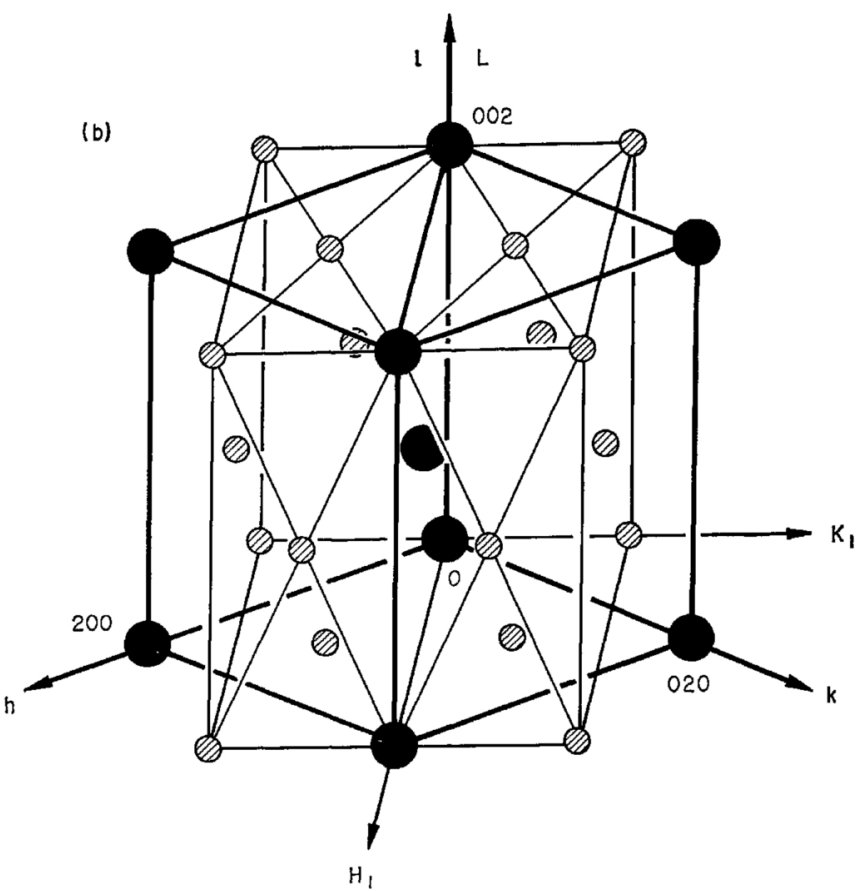

Fig. 3 (b) Reciprocal lattice of $\mathrm{Ni}_{2} \mathrm{Cr}$, showing a single orientation of superlattice by thin lines. Full and shaded circles are the fundamental and superlattice spots, respectively

orientations, the bright regions in this picture correspond merely to one sixth of the existing domains, but the domains with other five orientations are not excited. The ordered regions with two different orientations can actually be recognized in the dark-field images formed by superlattice spots in the $(\overline{1} 12)_{c}$ reciprocal plane. Photos. 3 (b) and (c) were the dark-field micrographs formed by the superlattice spots of $\left(\begin{array}{lll}1 & 1 / 3 & 1 / 3\end{array}\right)_{c}$ and $(2 / 3 \overline{2} / 3 \quad 0)_{c}$, 


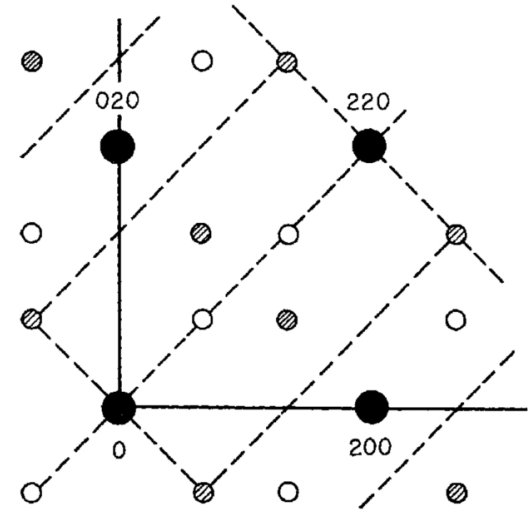

(o)

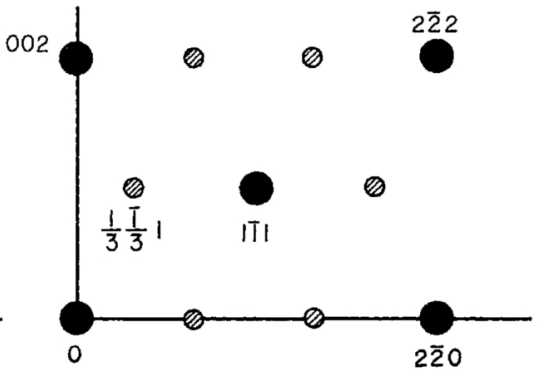

(b)

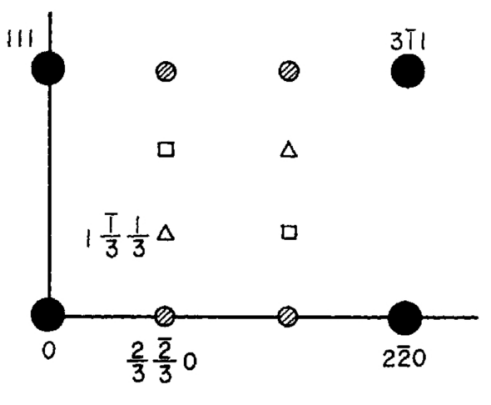

(c)

Fig. 4 (a), (b) and (c) are the reciprocal lattice planes of $(001)_{c},(110)_{c}$ and $(112)_{c}$, respectively. Open circles, shaded circles, triangles and squares are the superlattice spots with different orientations. Full circles are the fundamental spots
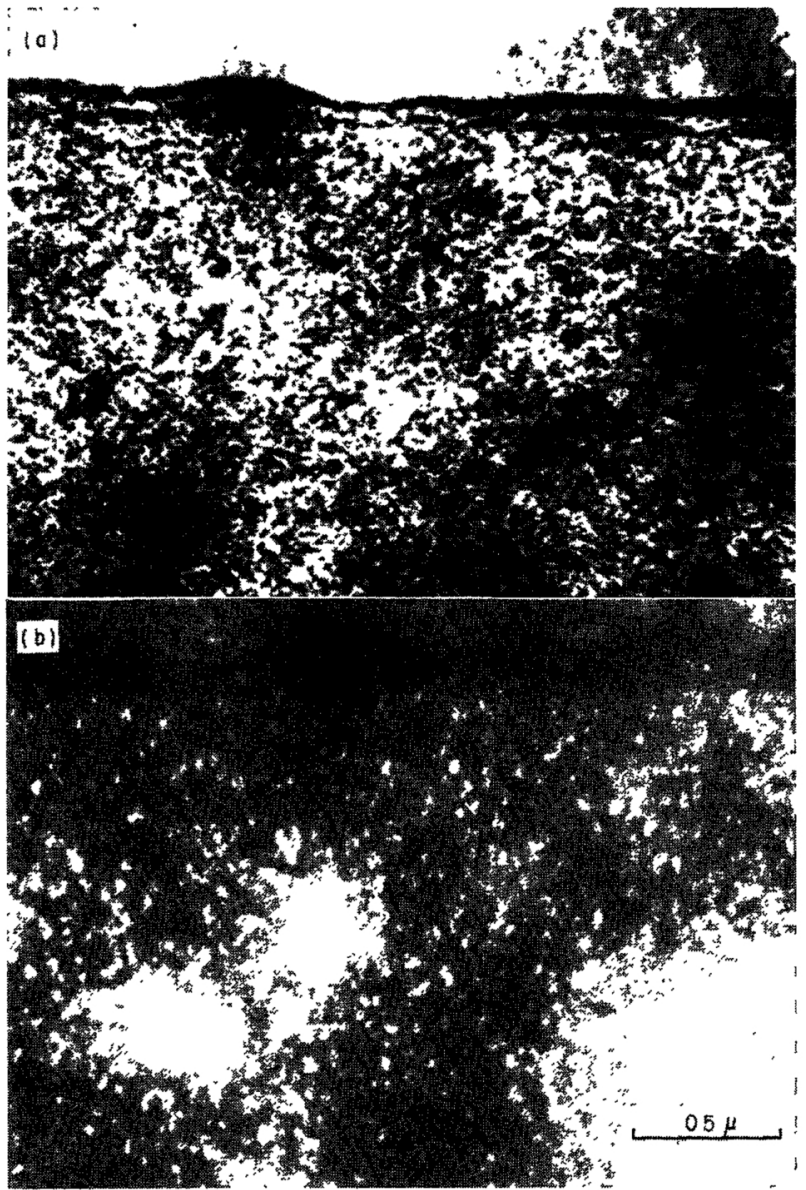

Photo. 2 Electron micrographs of $33.3 \% \mathrm{Cr}$ alloy with $(110)_{c}$ orientation, annealed at $460^{\circ} \mathrm{C}$ for $1600 \mathrm{hr}$ after quenching from $1000^{\circ} \mathrm{C}$

(a) : Bright - field image

(b) : Dark-field image formed by $(1 / 3 \overline{1} / 31)_{c}$ spot

respectively. Different regions are excited in these photographs, since the two reflections arise from the ordered regions with different orientations as illustrated in Fig. 4 (c). It is noticed in the electron micrographs of Photos. 2 and 3 that the ordered domains are as small as about $500 \AA$, even after a prolonged ordering treatment, and the boundaries do not seem to be restricted to any particular crystallographic planes. These domains give rise to irregular diffraction contrasts in bright-field images as seen in Photos. 2 (a) and 3 (a). The findings

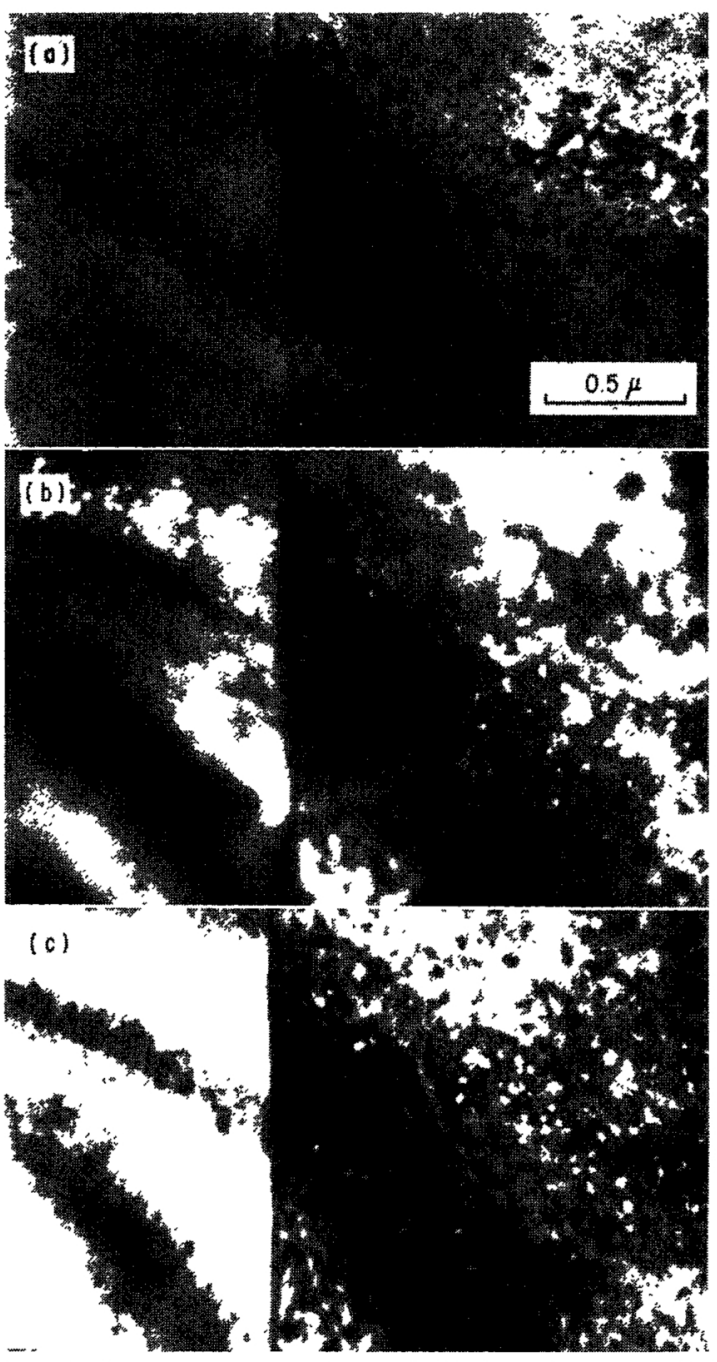

Photo. 3 Electron micrographs of $33.3 \% \mathrm{Cr}$ alloy with $(\overline{11} 2)_{c}$ orientation. Heat-treatment is the same as in Photo. 2. (a) : Bright-field image, (b) and (c) : Dark-field images formed by $(1 \overline{1} / 31 / 3)_{c}$ and $(2 / 3 \overline{2} / 30)_{c}$ spots, respectively

just described are also obtained on the other specimens with 32.9 and 35.2 at $\% \mathrm{Cr}$.

The lattice constants of the alloys with 33.3 and 35.2 at \% $\mathrm{Cr}$ were measured by an X-ray diffraction technique for both the ordered and disordered states as listed in Table 1. The lattice contraction due to ordering is noted 
here. Since neither rhombic splitting nor broadening of the diffraction lines could be detected in the fully annealed state, the lattice parameter of the ordered alloy is given in terms of the original cubic coordinate.

Table 1 Lattice constants of the cubic cell (̊)

\begin{tabular}{c|c|c|c|c}
\hline $\begin{array}{c}\text { Composition } \\
(\text { at\% Cr) }\end{array}$ & \multicolumn{2}{|c|}{ Disordered state } & \multicolumn{2}{c}{ Ordered state } \\
\hline 33.3 & 3.566 & $\begin{array}{c}\text { Quenched } \\
\text { from } 1000^{\circ} \mathrm{C}\end{array}$ & 3.562 & $\begin{array}{c}\text { Annealed at } \\
460^{\circ} \mathrm{C} \text { for } 3200 \mathrm{hr}\end{array}$ \\
35.2 & 3.560 & $485^{\circ} \mathrm{C}$ for $670 \mathrm{hr}$ \\
\hline
\end{tabular}

those of previous workers ${ }^{(1)(6)(10)}$.

\section{Superdislocations}

Electron microscopy revealed the existence of triple superdislocations, though not so frequent, in various stages of ordering. The electron micrographs of Photos. 5 (a) and (b) exhibit triple superdislocations observed in the alloy, 32.1 at $\% \mathrm{Cr}$, annealed for $48 \mathrm{hr}$ and in the alloy, 33.3 at $\% \mathrm{Cr}$, annealed for $2400 \mathrm{hr}$ at $500^{\circ} \mathrm{C}$, respectively. It is noticed in Photo. 5 (a) that the separation between the first and second dislocations $\left(r_{1}\right)$ is larger than that between the second and third ones $\left(r_{2}\right)$.

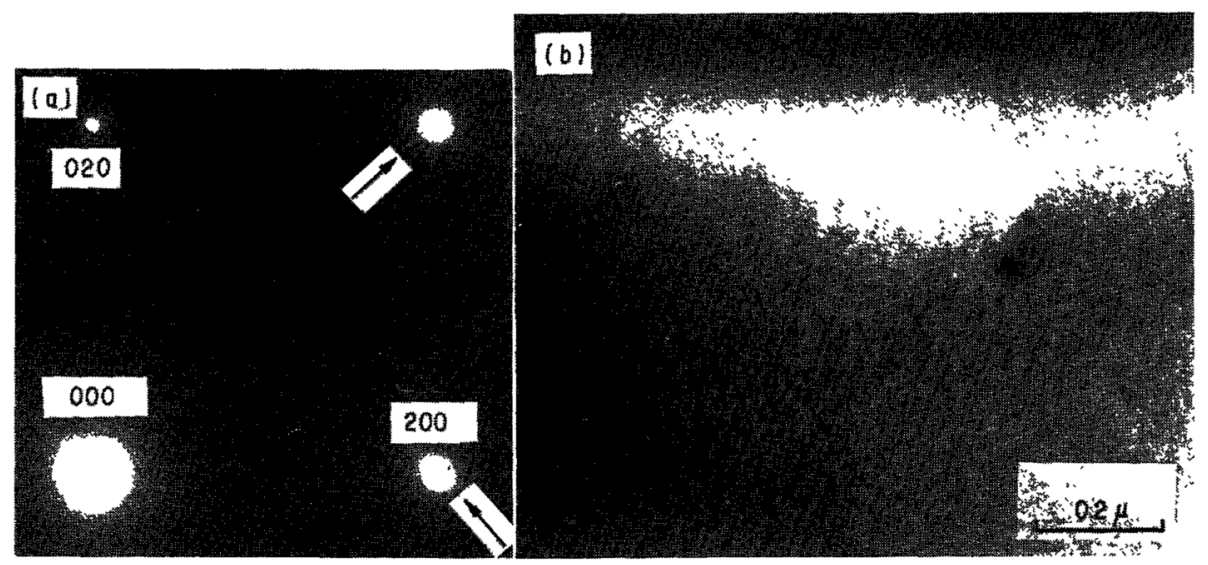

Photo. 4 Electron-diffraction pattern (a) and bright-field image (b) of $33.3 \% \mathrm{Cr}$ alloy annealed at $500^{\circ} \mathrm{C}$ for $48 \mathrm{hr}$ after quenching from $1000^{\circ} \mathrm{C}$. Arrows in (a) indicate diffuse scatterings

\section{Isothermal ordering around $500^{\circ} \mathrm{C}$}

Referring to the resistivity change measured at liquidnitrogen temperature, various stages of isothermal ordering near $500^{\circ} \mathrm{C}$ were studied by means of electron microscopy and electron diffraction. As shown in Fig. 5 (a), the electrical resistivity first increases slightly (the $K$-state) and then decreases with increasing annealing time in agreement with the previous works ${ }^{(1)(6)}$. Superlattice spots were hardly observed up to an annealed state corresponding to the end of the plateau of resistivity curves. In the $K$-state, however, the fundamental spots are accompanied by weak diffuse scattering parallel to $<110\rangle$ directions, and irregular tweed contrasts appear in the bright-field image, as shown in Photos. 4 (a) and (b), respectively. These phenomena may be a manifestation of lattice modulation or distortion due to the initiation of ordering from the disordered state, as in the case of $\mathrm{CuAu}^{(13)}$. In comparison with the latter system, however, no superlattice reflections could be observed in $\mathrm{Ni}_{2} \mathrm{Cr}$, probably because of the close scattering factors of the constituent elements.

Changes in hardness and yield strength of the alloy of 35.2 at $\% \mathrm{Cr}$ are plotted against annealing time at $485^{\circ} \mathrm{C}$ in Fig. $5(\mathrm{~b})$. The alloy becomes hardened considerably after keeping for more than about $100 \mathrm{hr}$, but only a small increase in strength occurs in the $K$-state. It was observed that the stress-strain curves for the disordered and ordered states are almost parallel after yielding, indicating that the hardening rate is scarcely affected by the atomic ordering. These results are consistent with

(13) M. Hirabayashi and S. Weissmann : Acta Met., 10(1962), 25.

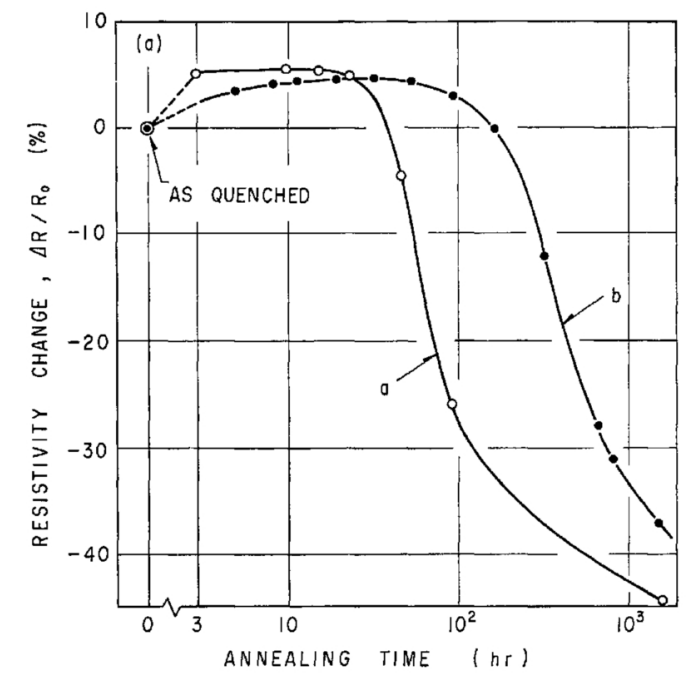

Fig. 5 (a) Changes in electrical resistivity at $-196^{\circ} \mathrm{C}$ during isothermal annealing after quenching from $1000^{\circ} \mathrm{C}$. Curves (a) and (b) correspond to the alloys of 32.1 and $35.2 \% \mathrm{Cr}$ annealed at $500^{\circ} \mathrm{C}$ and $485^{\circ} \mathrm{C}$, respectively

The values of $r_{1}$ and $r_{2}$ in this electron micrograph are estimated to be about 1000 and $400 \AA$, respectively. In Photo. 5 (b), the separations seem to be nearly equal in each group, ranging between 200 and $700 \AA$. Triple dislocations were also observed in the 35.2 at \% $\mathrm{Cr}$ alloy annealed for more than $710 \mathrm{hr}$. In this case, the spacings are of an order of magnitude of a few hundred $\AA$, which seems relatively large in comparison with the stoichiometric alloy. However, the occurrence of triple 


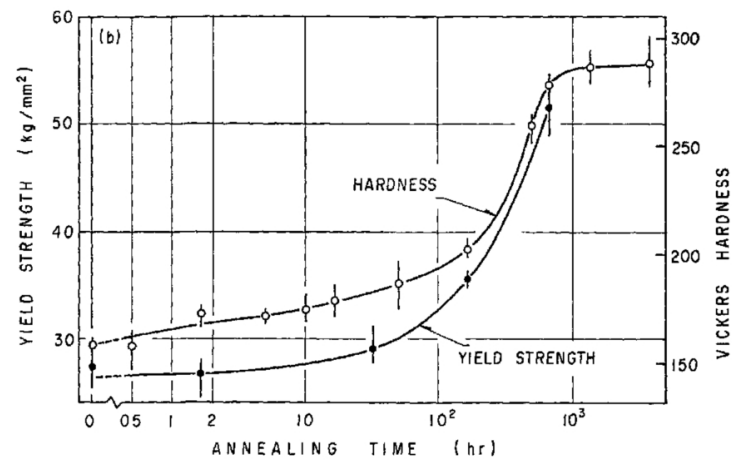

Fig. 5 (b) Changes in hardness and yield strength of $35.2 \% \mathrm{Cr}$ alloy with annealing time at $485^{\circ} \mathrm{C}$ after quenching from $980^{\circ} \mathrm{C}$ and of the superdislocation will be discussed. As mentioned before, the orthorhombic phase with six different orientations will be formed from the original cubic solid solution during the ordering process. Further there should be three kinds of ordered domains for each of these orientations, because the superlattice of $\mathrm{Ni}_{2} \mathrm{Cr}$ can be resolved into three sublattices of the body-centered orthorhombic call. Therefore, eighteen kinds of ordered domains are formed, thus creating numerous types of anti-phase boundaries at the interfaces of these domains. As shown in Photos. 2 and 3, the size of domains does not exceed $1000 \AA$ even in the fully annealed state, which is slightly smaller than the estimate $(\sim 1200 \AA)$ from the line wiơth of neutron diffraction patterns by Goman'kov

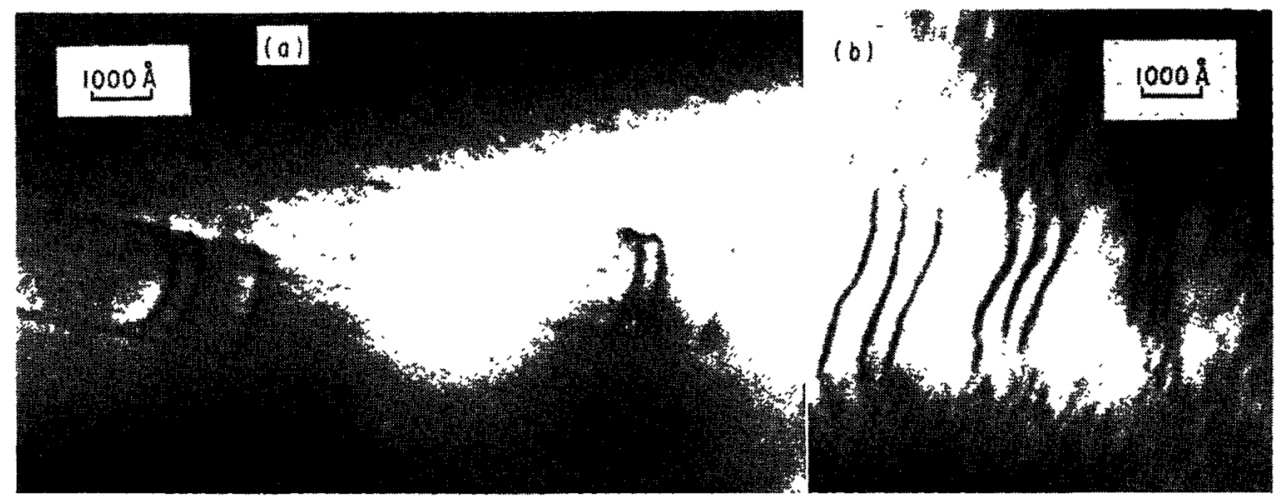

Photo. 5 Superdislocations in $\mathrm{Ni}_{2} \mathrm{Cr}$, annealed at $500^{\circ} \mathrm{C}$ for $48 \mathrm{hr}(32.1 \% \mathrm{Cr}$ ) (a), and for $2400 \mathrm{hr}(33.3 \% \mathrm{Cr})$ (b)

dislocations is rather seldom, and most of the observed dislocations in the ordered state were single dislocations.

\section{Discussion}

The theory of Shtremel(11) based upon the BraggWilliams approximation gives the following relations among the ordering energy $v\left(=v_{\mathrm{AA}}+v_{\mathrm{BB}}-2 v_{\mathrm{AB}}\right)$, the transition temperature $T_{c}$, and the heat of transformation $E_{0}$ for the stoichiometric alloy $\mathrm{A}_{2} \mathrm{~B}$, i.e.

$$
\left.\begin{array}{l}
k T_{c}=0.68 v \\
E_{0}=\frac{v}{3},
\end{array}\right\}
$$

where $k$ is the Boltzmann constant. Consequently if we take $T_{c}=863^{\circ} \mathrm{K}$ from the experiment, the heat of transformation $E_{0}$ will be $840 \mathrm{cal} / \mathrm{g} \cdot$ atom, which is somewhat smaller than the observed value $(\sim 1000 \mathrm{cal} / \mathrm{g} \cdot$ atom $)$. The ordering energy $v$ is evaluated roughly as $2.5 \sim 3.0$ $\mathrm{kcal} / \mathrm{g} \cdot$ atom.

According to the theory, the transformation of the stoichiometric $\mathrm{A}_{2} \mathrm{~B}$ alloy is of a first order accompanied by a latent heat $\Delta S^{2} E_{0}$ at the critical point, where $\Delta S$ $(\simeq 0.3)$ is the decrement in the degree of long-range order at this temperature. Thus, in this case, the latent heat of the order of $80 \mathrm{cal} / \mathrm{g} \cdot$ atom would appear. It may practically be impossible, however, to detect such a minor quantity of the latent heat by means of the heating calorimeter because of the extremely slow reaction of this transformation.

Next specific features of the ordered domain structure et al. ${ }^{(3)}$

The spacings of triple dislocations have been calculated by Popov and Kozlov ${ }^{(9)}$ as a function of energy $\gamma$ of antiphase boundaries left behind after the movement of the dislocations, i.e.

$$
\begin{aligned}
& r_{1}=\frac{\sqrt{3} G b^{2}}{2 \pi x \gamma} \\
& r_{2}=\frac{\sqrt{3} G b^{2}}{2(1+\sqrt{3}) \pi x \gamma},
\end{aligned}
$$

where $G$ is the rigidity modulus, $b$ is the Burgers vector and $x$ is equal to $(1-\nu)$ for pure edge dislocation and 1 for pure screw dislocation ( $\nu$ is the Poisson's ratio). In the case of a perfect order, the boundary energy is given as,

$$
\gamma=\frac{1}{9} N^{\prime} Z^{\prime} v
$$

where $N^{\prime}$ is the number of atoms per unit area in the slip plane, $Z^{\prime}$ is the number of nearest neighbors at an atom in a neighboring plane. Taking the ordering energy as $v=2.5 \mathrm{kcal} / \mathrm{g} \cdot$ atom and putting in all the necessary values, $\gamma$ is obtained as about $110 \mathrm{ergs} / \mathrm{cm}^{2}$. Substituting this value in eq. (4), we will obtain 120 and $50 \mathrm{~A}$ for the spacings $r_{1}$ and $r_{2}$ for screw dislocations, respectively. These values are smaller than the observation of Photo. 5 . The fact that the spacings in an early stage of ordering (Photo. 5 (a)) or in the off-stoichiometric alloy are considerably larger than the calculation is qualitatively explained as follows. The boundary energy is reduced if the atomic order is imperfect. Furthermore, as 
suggested by Popov et al. ${ }^{(9)}$, it may be reasonable to replace $\gamma$ by $\gamma / 3$ in eq. (4) if the domain size is considerably small in comparison with the spacings of dislocations, since merely one third of the anti-phase domains are responsible for the interaction with dislocations. Therefore, the spacings of superdislocations are increased in the imperfectly ordered state.

As mentioned before, no rhombic distortion other than the lattice contraction appears upon ordering, so that the lattice strain induced at the domain boundaries seems to contribute to the strengthening to relatively minor extent. The fact that the work-hardening rate of $\mathrm{Ni}_{2} \mathrm{Cr}$ is not appreciably affected by the ordering is consistent with the electron-microscopic observation that most dislocations move separately even in the ordered state. Therefore the major part of the large increment in strength of the ordered alloy $\mathrm{Ni}_{2} \mathrm{Cr}$ may be attributed to the formation of anti-phase boundaries left behind after the moving of single dislocations ${ }^{(9)}$.

\section{Summary}

The observed results on the nature of the ordered alloy $\mathrm{Ni}_{2} \mathrm{Cr}$ will be summarized as follows :

(1) The formation of the superstructure of the $\mathrm{Pt}_{2} \mathrm{Mo}$ type was revealed by electron diffraction, but the antiphase domains existing even in the fully annealed state were as small as less than $1000 \mathrm{~A}$.
(2) The heat of transformation was evaluated as about $1.0 \mathrm{kcal} / \mathrm{g} \cdot$ atom. The entropy change obtained was 1.2 $\mathrm{cal} / \mathrm{g} \cdot \mathrm{atom}-\mathrm{deg}$, in good agreement with the calculated configurational entropy.

(3) Triple superdislocations were observed in various stages of ordering, and the separations between dislocation lines were generally larger than the values evaluated from the ordering energy which was obtained from the calorimetric measurement.

\section{Acknowledgments}

The authors of Osaka University would like to thank Professor J. Awatani for allowing them to use the Instron testing machine. Their thanks are also due to Mr. K. Yagii for his assistance in the experimental works. The authors of Tohoku University wish to express their thanks to Mr. S. Yamaguchi for his help and discussion during the work.

Note added in proof : Recently Vintaikin and Vlasova (Sov. Phys.-Doklady, 13 (1969), 1066) observed diffuse scattering along the $\langle 110\rangle$ directions around the fundamental reflections in $\mathrm{X}$-ray patterns of a single crystal of 34.5 at $\%$ Cr. 